\title{
Another look at value and momentum: volatility spillovers
}

\author{
Klaus Grobys $^{1}$ (D) Sami Vähämaa ${ }^{1}$ (D)
}

Published online: 8 April 2020

(C) The Author(s) 2020

\begin{abstract}
This paper examines volatility interdependencies between value and momentum returns. Using U.S. data over the period 1926-2015, we document persistent periods of low and high volatility spillovers between value and momentum strategies. Moreover, we find that the intensity of the volatility spillovers may change substantially in very short periods of time and that these shifts in spillover intensity can be linked to prominent economic events and financial market turmoil. Our results further demonstrate that value returns increase and momentum returns decrease monotonically with increasing volatility spillovers between the two strategies. Given this linkage between spillover intensity and returns, we propose a simple trading strategy which utilizes a volatility spillover index for allocating funds between value and momentum portfolios. The proposed trading strategy outperforms value and momentum strategies and generates payoffs that are not subject to option-like behavior.
\end{abstract}

Keywords Asset pricing · Value effect · Momentum effect · Volatility spillovers · Volatility spillover index

JEL Classification $\mathrm{G} 11 \cdot \mathrm{G} 12 \cdot \mathrm{G} 14$

\section{Introduction}

Over the last 2 decades, considerable attention in asset pricing studies has been devoted to the performance and risk characteristics of value and momentum strategies. As noted by Asness et al. (2013), value and momentum effects in stock returns are two of the most examined financial market anomalies which have now become focal points of the asset pricing literature. These two strategies are also widely used by practitioners. In this paper, we aim to contribute to the literature by empirically examining volatility interdependencies between value and momentum returns.

Klaus Grobys

kgrobys@uva.fi

Sami Vähämaa

sami@uva.fi

1 School of Accounting and Finance, University of Vaasa, P.O. Box 700, 65101 Vaasa, Finland 
The value effect, that is the outperformance of stocks with high book-to-market equity ratios ("value stocks") relative to stocks with low book-to-market equity ratios ("growth stocks"), is one of the oldest investment paradigms which can be traced back to the classic book by Graham and Dodd (1934). The existence of the value premium has been widely documented in stock markets around the world (e.g., Capaul et al. 1993; Fama and French 1998, 2012; Bauman et al. 2001; Griffin 2002; Bartov and Kim 2004; Asness et al. 2013; Cakici et al. 2016; Pätäri et al. 2018), and the standard empirical asset pricing models of Fama and French $(1993,2015)$ have been designed to capture the value pattern in stock returns. ${ }^{1}$

The momentum effect, in turn, refers to the tendency of stocks with high short-term past returns ("winners") to outperform stocks with low past returns ("losers"). This anomalous continuation of short-term returns was first documented by Jegadeesh and Titman (1993), and has since been extensively explored in various international stock markets, across different types of stocks, industries, and asset classes as well as over different time periods (e.g., Rouwenhorst 1998; Moskowitz and Grinblatt 1999; Jegadeesh and Titman 2001; Fama and French 2008; Sapp 2011; Jiang et al. 2012; Yu 2012; Asness et al. 2013; Jostova et al. 2013; Barosso and Santa-Clara 2015; Hur and Singh 2016; Bhattacharya et al. 2017; Grobys et al. 2018). ${ }^{2}$

In this paper, we take a novel perspective on the value and momentum effects by focusing on volatility spillovers between these two strategies. The paper perhaps most directly related to ours is Asness et al. (2013), who examine co-movements of value and momentum returns within and across markets and asset classes. Using data on eight different markets and asset classes, Asness et al. (2013) find strong interdependencies between value and momentum returns, and moreover, document that value and momentum are negatively correlated with each other within and across asset classes. Overall, the empirical findings of Asness et al. (2013) suggest the presence of a common factor structure among value and momentum returns. Our study builds on Asness et al. (2013) by exploring the potential dynamic interdependencies between the second moments of value and momentum returns.

In addition to Asness et al. (2013), our empirical analysis is motivated by the prior studies on volatility spillover effects between different international stock markets and across different industries and size groups within markets (see e.g., Hamao et al. 1990; Chiang and Chiang 1996; Campbell et al. 2001; Ewing 2002; Harris and Pisedtasalasai 2006; Datar et al. 2008; Diebold and Yilmaz 2009; Gannon 2010; Wang 2010; Ben Sita 2013; Clements et al. 2015; Barunik et al. 2016). As noted in the literature, knowledge of potential volatility spillovers has important practical implications for the formulation and implementation of investment, diversification, and risk management strategies. Diebold and Yilmaz (2009), who proposed a framework for constructing volatility spillover indices, argue that any time variation in the intensity of spillovers is of considerable interest and importance for investors and financial economists. Despite the voluminous body of literature on volatility transmission across and within different segments of financial markets, volatility spillovers between value and momentum strategies have not been investigated in previous studies. The present paper seeks to fill this void.

In our empirical analysis, we use data on value and momentum factor portfolios of U.S. stocks over the period December 1926 through September 2015. The value factor

\footnotetext{
1 Pätäri and Leivo (2017) provide a rigorous survey of the value premium literature.

2 The literature on the momentum effect is reviewed in Swinkels (2004) and Galariotis (2014).
} 
portfolio is the standard Fama-French zero-cost long-short portfolio constructed based on the book-to-market equity ratios, while the momentum factor is the corresponding Fama-French zero-cost portfolio long on past winner stocks and short on past losers. We estimate monthly realized volatilities of the value and momentum returns, and then employ the volatility spillover index framework proposed by Diebold and Yilmaz (2009) to examine the intensity of volatility spillovers between the returns of value and momentum portfolios over time. Specifically, following Diebold and Yilmaz (2009), we use forecast-error variance decompositions associated with a vector autoregressive model to estimate volatility spillover effects between value and moment returns.

Our results demonstrate that the intensity of volatility spillovers between value and momentum strategies varies considerably over time. Consistent with the recent literature on volatility spillovers between different markets and asset classes (e.g., Diebold and Yilmaz 2009; Grobys 2015; Greenwood-Nimmo et al. 2016; Ribeiro and Curto 2017), we document persistent periods of low as well as high volatility spillovers between value and momentum returns. Interestingly, we also find that the intensity of the spillovers may change substantially in very short periods of time. These sudden shifts in volatility spillover intensity can be, at least to some extent, linked to specific economic and geopolitical events and periods of severe financial market turmoil. In the aftermath of major events, the volatilities of both strategies are more likely to be driven by a common uncertainty factor, whereas periods of low volatility spillover intensity tend to coincide with economic recessions.

Furthermore, our results indicate that the average value returns increase and the average momentum returns decrease monotonically with increasing volatility spillover intensity between the two strategies. Given this linkage between volatility spillovers and returns, we propose a simple trading strategy which utilizes the expected intensity of volatility spillovers for allocating funds between value and momentum portfolios. This trading strategy uses a 1-month-ahead forecast of volatility spillovers as a trading signal, and allocates funds into momentum in low volatility spillover intensity regimes and into value in high spillover intensity regimes. We show that the proposed trading strategy outperforms and provides considerably higher Sharpe ratios than value and momentum strategies. Moreover, the volatility spillover strategy also outperforms the 50/50 value and momentum combination strategy previously examined in Asness et al. (2013). Perhaps more interestingly, our results indicate that the trading strategy based on expected volatility spillovers generates payoffs that are not subject to option-like behavior and so-called momentum crashes recently documented e.g., in Daniel and Moskowitz (2016) and Grobys et al. (2018).

The remainder of this paper proceeds as follows. Section 2 describes the data and the construction of the volatility spillover index. Section 3 focuses on the dynamics of volatility spillovers between value and momentum strategies over time. In Sect. 4, we examine the linkage between volatility spillovers and future returns of value and momentum portfolios, and in Sect. 5 we propose a simple trading strategy based on the intensity of volatility spillovers. Finally, Sect. 6 summarizes the paper and provides concluding remarks. 
Table 1 Descriptive statistics for value and momentum volatilities

\begin{tabular}{lll}
\hline & Value & Momentum \\
\hline Mean & 7.33 & 11.66 \\
Median & 2.82 & 4.26 \\
Maximum & 154.17 & 390.71 \\
Minimum & 0.29 & 0.19 \\
SD & 14.69 & 25.26 \\
Skewness & 4.89 & 6.68 \\
Kurtosis & 32.95 & 69.96 \\
No. of obs. & 1066 & 1066 \\
\hline
\end{tabular}

The table reports descriptive statistics for the monthly realized volatilities of the value and momentum factor portfolios. The monthly realized volatilities are estimated from daily return data on the zero-cost long-short value and momentum portfolios. The sample period is from December 1926 to September 2015

\section{The empirical setup}

\subsection{Data and realized volatilities}

The data used in our empirical analysis consist of daily and monthly returns on the Fama-French value and momentum factor portfolios of U.S. stocks and the CRSP market index. These return data are obtained from Kenneth R. French's data library. ${ }^{3}$ The value factor is a zero-cost long-short portfolio constructed based on six value-weighted portfolios formed on size and book-to-market equity ratios. Specifically, the value factor return equals the average return on the two value stock portfolios minus the average return on the two growth stock portfolios that are controlled for three size groups. The momentum factor, in turn, is a zero-cost long-short portfolio constructed based on four value-weighted portfolios formed on size and cumulative short-term past returns. This portfolio is long on past winners and short on past losers. The sorting procedures utilized in the construction of the value and momentum factor portfolios employ all individual stocks listed at NYSE, AMEX, and NASDAQ. The sample period used in our analysis extends from December 1926 to September 2015, for a total of 1066 monthly observations.

We examine volatility spillovers between value and momentum strategies based on realized return volatilities. Specifically, we use daily return data to estimate realized volatilities of the value and momentum portfolios for each month as follows:

$$
\operatorname{REVOL}_{i, t}=M \sqrt{\frac{1}{M} \sum_{k=1}^{M} r_{i, k}^{2}},
$$

where $M$ denotes the number of trading days in month $t, i$ denotes the strategy with $i=\{$ value, momentum $\}$, and $r_{i, k}^{2}$ is the squared return of strategy $i$ on day $k$ in month $t$.

Table 1 reports descriptive statistics for the estimated realized volatilities of the value and momentum factor portfolios. It can be noted from the table that momentum returns

\footnotetext{
3 The data used in our empirical analysis are publicly available on Kenneth R. French's data library at http://mba.tuck.dartmouth.edu/pages/faculty/ken.french/data_library.html.
} 
exhibit much higher volatility than value returns. Both the mean and the median unconditional realized volatilities of the momentum factor portfolio are more than $50 \%$ higher than the mean and the median volatilities of the value portfolio, and also the maximum monthly momentum volatility of about $391 \%$ is more than twice as high as the maximum of the value strategy. Interestingly, the maximum monthly volatility of the momentum strategy occurred in September 1939 concomitantly with the outbreak of the World War II. During that month, the value strategy generated a positive return of $22 \%$, while the momentum strategy crashed, in the parlance of Daniel and Moskowitz (2016), with a monthly return of $-30.45 \%$. The descriptive statistics in Table 1 further indicate that the time-series of realized momentum volatility is highly leptokurtic and also more positively skewed than the volatility of value returns. Over our sample period, the unconditional correlation between the monthly realized value and momentum volatilities is 0.63 , suggesting a strong linkage between the volatilities of the two strategies.

\subsection{Volatility spillover index}

We employ the volatility spillover index framework proposed by Diebold and Yilmaz (2009) to examine volatility spillovers between value and momentum returns. Specifically, we estimate the following vector autoregressive model:

$$
\mathbf{Y}_{t}=\mathbf{c}+\mathbf{A}_{1} \mathbf{Y}_{\mathrm{t}-1}+\cdots+\mathbf{A}_{\mathbf{p}} \mathbf{Y}_{\mathrm{t}-\mathrm{p}}+\mathbf{E}_{\mathrm{t}}
$$

where $\mathbf{Y}_{\mathbf{t}}=\left(R E V O L_{\text {value }, t}, R E V O L_{\text {momentum }, t}\right)^{\prime}$ is a $2 \times 1$ vector containing the realized volatilities of the value and momentum factor portfolios, $\mathbf{A}_{1}, \ldots,+\mathbf{A}_{\mathbf{p}}$ denote $2 \times 2$ parameter matrices, $\mathbf{c}$ is a $2 \times 1$ vector containing the constant terms, and the error term $\mathbf{E}_{\mathbf{t}}$ is assumed to be distributed as multivariate normal with $\mathbf{E}_{\mathbf{t}} \sim \operatorname{MVN}\left(\mathbf{0}, \Sigma_{\mathbf{u}}\right)$, where $\boldsymbol{\Sigma}_{\mathbf{u}}$ is the corresponding covariance matrix. In order to ensure that our results are not particularly sensitive to different lags, we employ lag-orders 2, 4, and 6 for $p$ in the estimations.

Following Diebold and Yilmaz (2009), after estimating the vector autoregressive model given by Eq. (2), we employ the estimated parameter matrices $\hat{\mathbf{A}}_{\mathbf{1}}, \ldots, \hat{\mathbf{A}}_{\mathbf{p}}$ to model the corresponding Wold moving average (MA) representation:

$$
\mathbf{Y}_{\mathbf{t}}=\boldsymbol{\Phi}_{\mathbf{0}} \mathbf{u}_{\mathrm{t}}+\boldsymbol{\Phi}_{1} \mathbf{u}_{\mathrm{t}-1}+\boldsymbol{\Phi}_{2} \mathbf{u}_{\mathrm{t}-2}+\cdots,
$$

where $\boldsymbol{\Phi}_{0}=\mathbf{I}_{2}$ and

$$
\boldsymbol{\Phi}_{\mathbf{s}}=\sum_{\mathbf{j}=\mathbf{1}}^{\mathbf{s}} \boldsymbol{\Phi}_{\mathbf{s}-\mathbf{j}} \hat{\mathbf{A}}_{\mathbf{j}} \quad \text { with } s=1,2, \ldots
$$

is compounded recursively. Furthermore, we use the Cholesky decomposition of the covariance matrix $\boldsymbol{\Sigma}_{\mathbf{u}}$ which we define as matrix $\mathbf{B}$. If $\mathbf{B}$ is a lower triangular matrix such that $\boldsymbol{\Sigma}_{\mathbf{u}}=\mathbf{B} \mathbf{B}^{\prime}$, the orthogonalized shocks are given by $\boldsymbol{\varepsilon}_{\mathbf{t}}=\mathbf{B}^{-\mathbf{1}} \mathbf{u}_{\mathbf{t}}$. Consequently, we obtain:

$$
Y_{t}=\Psi_{0} \varepsilon_{t}+\Psi_{1} \varepsilon_{t-1}+\Psi_{2} \varepsilon_{t-2}+\cdots
$$

where $\boldsymbol{\Psi}_{\mathbf{i}}=\boldsymbol{\Phi}_{\mathbf{i}} \mathbf{B}$ with $i=0,1,2, \ldots$

Since $\Psi_{\mathbf{0}}=\mathbf{B}$ is a lower triangular matrix, a shock occurring on the first variable has an instantaneous effect on the second variable in the system. From Eq. (4), we can define the $h$-step forecast error as follows: 


$$
y_{k, T+h}-y_{k, T+h \mid T}=\boldsymbol{\Psi}_{\mathbf{0}} \boldsymbol{\varepsilon}_{\mathbf{T}+\mathbf{h}}+\boldsymbol{\Psi}_{\mathbf{1}} \boldsymbol{\varepsilon}_{\mathbf{T}+\mathbf{h}-\mathbf{1}}+\cdots+\boldsymbol{\Psi}_{\mathbf{h}-\mathbf{1}} \boldsymbol{\varepsilon}_{\mathbf{T}+\mathbf{1}}
$$

Furthermore, if we denote the $i j$ th element of $\boldsymbol{\Psi}_{\mathbf{n}}$ by $\psi_{i j, n}$, the $k$ th element of the forecast error vector becomes the following:

$$
y_{k, T+h}-y_{k, T+h \mid T}=\sum_{n=0}^{h-1}\left(\psi_{k 1, n} \varepsilon_{1, T+h-n}+\cdots+\psi_{k K, n} \varepsilon_{K, T+h-n}\right),
$$

with a corresponding forecast error variance of:

$$
\sigma_{k}^{2}(h)=\sum_{n=0}^{h-1}\left(\psi_{k 1, n}^{2}+\cdots+\psi_{k K, n}^{2}\right)=\sum_{j=1}^{K}\left(\psi_{k j, 0}^{2}+\cdots+\psi_{k j, h-1}^{2}\right) .
$$

In our context, the term $\left(\psi_{k j, 0}^{2}+\cdots+\psi_{k j, h-1}^{2}\right)$ can be interpreted as the contribution of the volatility of the value factor portfolio to the $h$-step forecast error variance of the volatility of the momentum factor portfolio. When compounding the $h$-step forecast error variance, we stuck the elements in a $2 \times 2$ matrix defined as $\boldsymbol{\Theta}_{k}^{2}(h)$. Following Diebold and Yilmaz (2009) and Grobys (2015), we construct the volatility spillover index between the value and momentum factor portfolios by summing up all elements above and below the main diagonal of $\boldsymbol{\Theta}_{k}^{2}(h)$ and dividing it by the total sum of all elements in $\boldsymbol{\Theta}_{k}^{2}(h)$, which is the part of the volatilities of the value and momentum returns that is unexplained by their own volatilities.

Similar to Grobys (2015), we employ a rolling estimation window of 60 months and a forecast-error variance decomposition using a horizon of 1 month (i.e., $h=1$ ). We update our rolling-window estimates at the beginning of each month to obtain 1-month-ahead forecasts of volatility spillovers between the value and momentum portfolios over the period December 1931 to September 2015.

\section{Volatility spillovers between value and momentum returns}

Panel A of Table 2 reports descriptive statistics for the estimated volatility spillover indices between the value and momentum factor portfolios with three different lag-orders $(p=2,4$, or 6), and Panel B presents the corresponding statistics for monthly changes in the spillover indices. In general, the descriptive statistics indicate that our estimates of volatility spillover intensity are not particularly sensitive to the selection of the lag-order. Regardless of the lag-order, the mean (median) level of the spillover index is roughly $0.40(0.35)$, and the spillover indices, on average, remain unchanged over time. Nevertheless, the minimums and maximums in Panel B demonstrate that the intensity of volatility spillovers between value and momentum portfolios can occasionally change very substantially from month to month.

Figure 1 depicts the moving 1-month-ahead volatility spillover indices between the value and momentum returns with three different lag-orders. Several interesting features emerge from the figure. First, it can be observed that the intensity of volatility spillovers between value and momentum returns varies considerably over time. As noted above from Table 2, the average level of the spillover index is roughly 0.40 regardless of the lag-order, but Fig. 1 shows that the indices display sustained periods of very low and very high volatility spillovers. This suggests that there are persistent regimes in the intensity of 
Table 2 Descriptive statistics for volatility spillover indices

\begin{tabular}{llll}
\hline \multicolumn{4}{c}{ Lag-order } \\
\cline { 2 - 3 } & $p=2$ & $p=4$ & $p=6$ \\
\hline Panel A: Volatility spillover indices & & \\
Mean & 0.39 & 0.38 & 0.40 \\
Median & 0.33 & 0.30 & 0.35 \\
Maximum & 0.95 & 0.98 & 1.00 \\
Minimum & 0.00 & 0.00 & 0.00 \\
SD & 0.28 & 0.27 & 0.28 \\
Skewness & 0.37 & 0.47 & 0.20 \\
Kurtosis & 1.89 & 2.04 & 1.79 \\
No. of obs. & 1006 & 1006 & 1006 \\
Panel B: Monthly changes in volatility spillover indices & \\
Mean & 0.00 & 0.00 & 0.00 \\
Median & 0.00 & 0.00 & 0.00 \\
Maximum & 0.55 & 0.58 & 0.61 \\
Minimum & -0.57 & -0.58 & -0.67 \\
SD & 0.07 & 0.08 & 0.09 \\
Skewness & -1.35 & -0.88 & -0.87 \\
Kurtosis & 22.97 & 22.19 & 16.29 \\
No. of obs. & 1005 & 1005 & 1005 \\
\hline
\end{tabular}

The table reports descriptive statistics for descriptive statistics for the volatility spillover indices between the value and momentum factor portfolios with three different lag-orders $(p=2$, 4, or 6). Panel A reports the descriptive statistics for levels of the volatility spillover indices, while Panel B reports the corresponding descriptives for the monthly changes in spillover indices. The sample period is from December 1931 to September 2015

volatility spillovers. Similar types of persistent periods of low and high volatility spillovers have been previously documented for spillovers between different markets and asset classes (e.g., Diebold and Yilmaz 2009; Grobys 2015; Greenwood-Nimmo et al. 2016; Ribeiro and Curto 2017). It is also apparent from Fig. 1 that the intensity of the volatility spillovers between value and momentum strategies may shift substantially in very short periods of time. For instance, at the onset of the global financial crisis in the summer of 2007, the volatility spillover indices abruptly dropped to almost zero after having been close to one for the previous 2-year period.

Furthermore, Fig. 1 shows that the volatility spillover indices exhibit very similar stochastic patterns irrespective of which lag-order is used in the estimation. This further suggests that our estimation results are not sensitive to the selection of the lag-order. We employ principal component analysis to explore the degree of co-movements between the three different volatility spillover indices. The PCA estimates demonstrate that there is one dominant eigenvalue with the value of 2.70. The first principal component explains roughly $90 \%$ of the total variance, and thereby confirms that a common factor governs the observed time-variation in the estimated volatility spillover indices.

Table 3 reports the pairwise correlations of the first principal component of the volatility spillover indices (VSPC) with the returns of the value and momentum factor portfolios, 


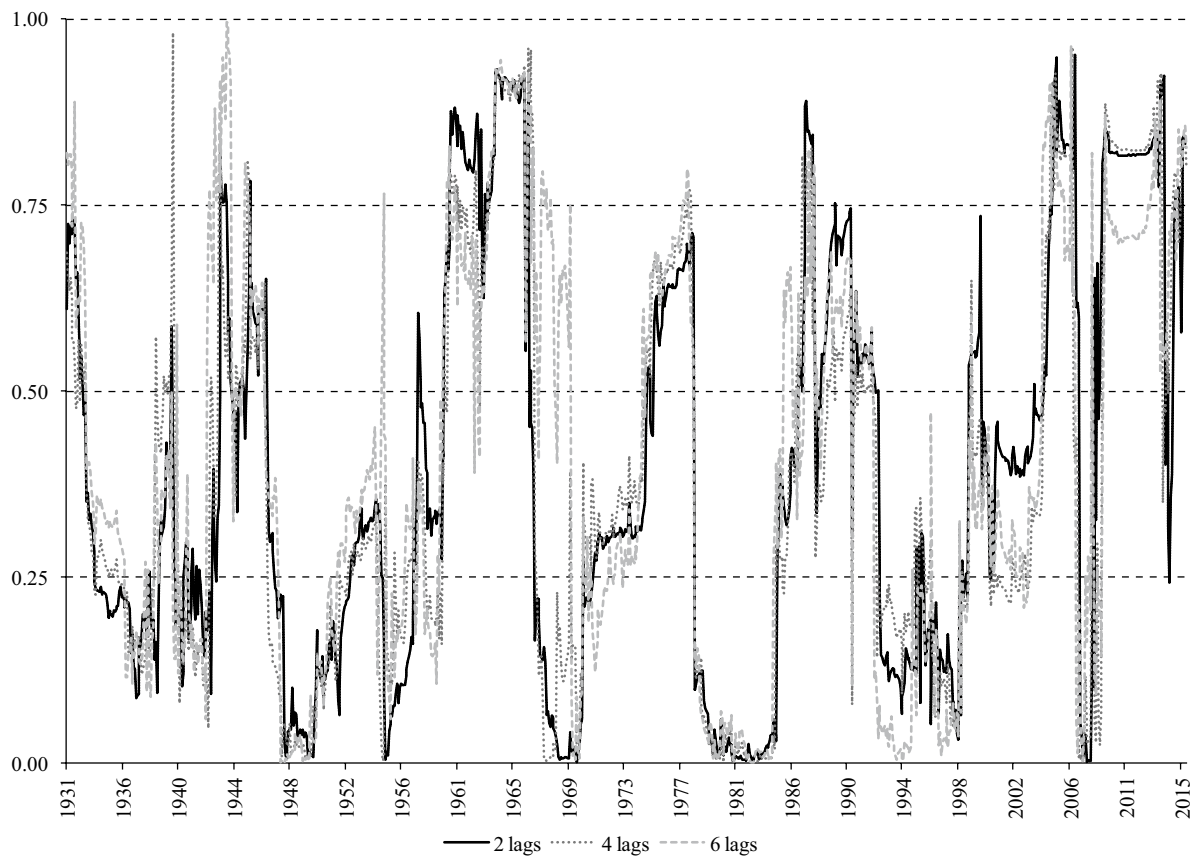

Fig. 1 Volatility spillover indices with different lag-orders. The figure plots the moving 1-month-ahead volatility spillover indices between the value and momentum factor portfolios with three different lag-orders ( $p=2$, 4, or 6) over the period December 1931 to September 2015

Table 3 Correlations

\begin{tabular}{|c|c|c|c|c|c|}
\hline & Value & Momentum & Market index & Market volatility & Recession \\
\hline$V S P C$ & 0.01 & -0.02 & 0.02 & 0.02 & -0.12 \\
\hline Value & & -0.39 & 0.10 & 0.00 & 0.02 \\
\hline Momentum & & & -0.11 & -0.11 & -0.10 \\
\hline Market index & & & & 0.06 & -0.10 \\
\hline Market volatility & & & & & 0.25 \\
\hline
\end{tabular}

The table reports correlation coefficients between six different time-series over the period 1931-2015. $V S P C$ is the first principal component of three volatility spillover indices between the value and momentum factor portfolios with different lag-orders $(p=2,4$, or 6$)$, Value is the monthly return for the value factor portfolio, Momentum is the monthly return for the momentum factor portfolio, Market index is the monthly excess return on the market index, Market volatility is the monthly stock market volatility based on a GARCH(1,1) model, and Recession is a dummy variable that equals one during National Bureau of Economic Research recessions

the excess market returns, and market volatility. As can be seen from the table, VSPC is virtually uncorrelated with excess market returns as well as with the returns of the value and momentum portfolios. A bit surprisingly, the correlation coefficients also indicate that VSPC is only weakly positively correlated with stock market volatility which is widely 


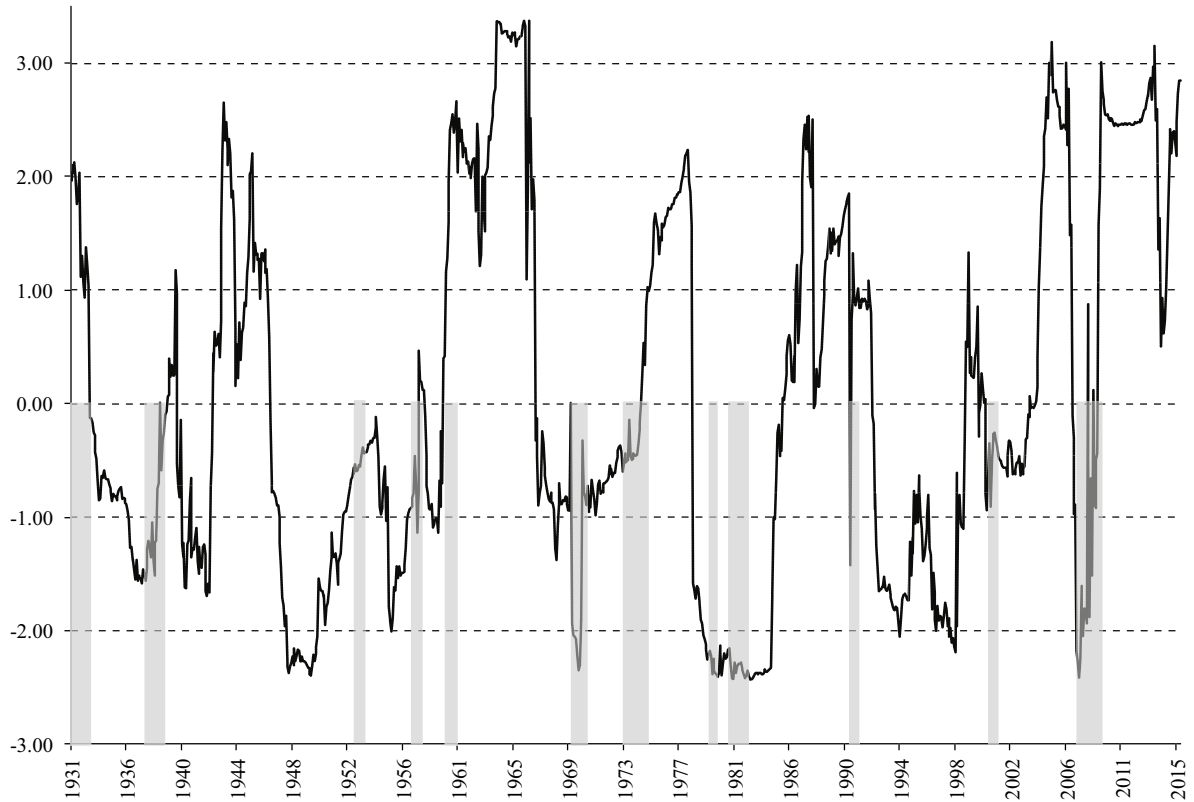

Fig. 2 Volatility spillovers and recessions. The figure plots the time-series of the first principal component of three volatility spillover indices. The three alternative volatility spillover indices between the value and momentum factor portfolios are estimated using different lag-orders $(p=2,4$, or 6$)$. The shaded grey areas indicate National Bureau of Economic Research recessions. The sample period is from December 1931 to September 2015

regarded as a measure of overall economic uncertainty. ${ }^{4}$ Nonetheless, it is important to recognize that VSPC measures the degree of co-movement between the two equity market risk factors. The co-movement can be high when correlations are either positive or negative, and thereby the concept of volatility spillovers is very different from market volatility. Consistent with the findings of Daniel and Moskowitz (2016), the correlations suggest that high stock market volatility is associated with low momentum returns, while the value factor appears to be uncorrelated with market volatility. Moreover, similar to Asness et al. (2013), Table 3 shows that momentum and value returns are strongly negatively correlated with each other.

Perhaps the most intriguing question for a financial economist is to investigate whether the observed time-variation in volatility spillovers can be linked to business cycles, crises periods, and distinct economic and geopolitical events. The findings of Diebold and Yilmaz (2009), for instance, demonstrate that the intensity of volatility spillovers between different stock markets is strongly affected by specific economic events and financial crises.

We begin by examining the effects of economic cycles on the intensity of volatility spillovers between the value and momentum strategies. To address this issue, we employ the first principal component of our three different volatility spillover indices and National Bureau of Economic Research (NBER) data on U.S. recession dates. The correlations reported in Table 3 provide suggestive evidence of a negative relationship between VSPC

${ }^{4}$ We use excess market returns and a GARCH$(1,1)$ model to estimate monthly stock market volatility. 


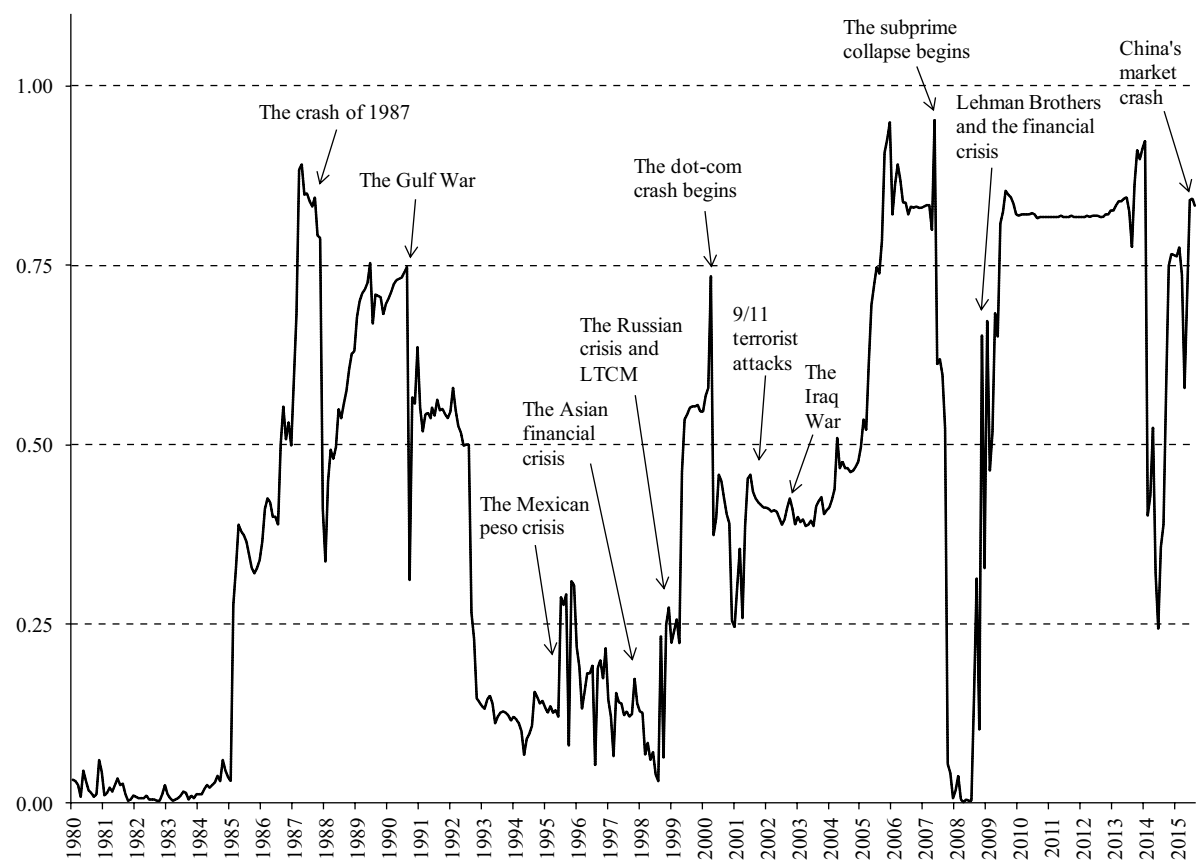

Fig. 3 Volatility spillovers and specific events. The figure plots the moving 1-month-ahead volatility spillover index between the value and momentum factor portfolios with lag-order $p=2$. The figure includes flags for major economic and geopolitical events and financial crises. The sample period is from January 1980 to September 2015

and NBER recession dates. In Fig. 2, we plot the eigenvector corresponding to the first principal component of volatility spillovers together with NBER recessions. The figure indicates that recessions tend to coincide with periods of low or declining volatility spillovers. Given the well-documented positive association between stock market volatility and recessions (e.g., Schwert 1989; Hamilton and Lin 1996), it is intriguing to observe that the linkage between value and momentum volatilities is weaker during recessions.

In order to investigate the relationship between recessions and volatility spillovers more formally, we estimate the following linear probit regression:

$$
\text { Recession }_{t}=\alpha_{0}+\alpha_{1} \operatorname{VSPC}_{t}+\varepsilon_{t},
$$

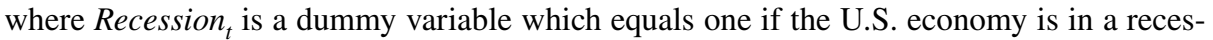
sion according to NBER in month $t$, and otherwise zero, and $V S P C_{t}$ is the first principal component of the three alternative volatility spillover indices. The point estimates for $\alpha_{0}$ and $\alpha_{1}$ are 0.14 and -0.03 , respectively, and statistically highly significant with heteroscedasticity-robust $t$ statistics of 13.3 and -4 .2. Thus, the estimated coefficients suggest that the economy is less likely to be in a recession during periods of more intense volatility spillovers between the value and momentum strategies. Overall, it can be concluded that the intensity of volatility spillovers seems to be linked to economic cycles.

Given that the previous studies have established strong linkages between volatility spillover indices and major economic and geopolitical events (see e.g., Diebold and Yilmaz 2009; Grobys 2015; Ribeiro and Curto 2017), we next explore the effects of distinct 
Table 4 Volatility spillovers and economic factors

\begin{tabular}{llcc}
\hline & $\begin{array}{l}\text { Economic policy } \\
\text { uncertainty }\end{array}$ & Consumer confidence & Market liquidity \\
\hline$V S P C$ & $0.44^{* * *}$ & $-0.33^{* * *}$ & $0.19^{* * *}$ \\
Economic policy uncertainty & & $-0.41^{* * *}$ & -0.08 \\
Consumer confidence & & & -0.01 \\
\hline
\end{tabular}

The table reports correlation coefficients between four different time-series over the period 1985-2015. VSPC is the first principal component of three volatility spillover indices between the value and momentum factor portfolios with different lag-orders $(p=2,4$, or 6$)$, Economic policy uncertainty is the economic policy uncertainty index of Baker et al. (2016), Consumer confidence is the U.S. consumer confidence index, and Market liquidity is the U.S. stock market liquidity measure of Pástor and Stambaugh (2003)

*** denotes statistical significance at the 0.01 level

episodes on the intensity of volatility spillovers between the value and momentum portfolios. For this purpose, Fig. 3 plots the time-series of the moving 1-month-ahead volatility spillover index with flags for well-known events and financial crises over the period January 1980 to September 2015. The figure illustrates that sudden changes in the volatility spillover index often coincide with major events and especially with periods of severe financial market turmoil. For example, the volatility spillover index rose rapidly before the stock market crash of October 1987 and then abruptly dropped to a much lower level immediately after the crash. The 1-month-ahead spillover index $(p=2$ and $h=1)$ was 0.85 in September 1987, while having being roughly 0.70 over the previous 12 -month period and well below 0.50 until August 1996.

Similarly, it can be observed from Fig. 3 that the volatility spillover index spiked just as the dot-com crash began in the spring of 2000. The volatility spillover index was 0.74 in April 2000, and dropped to 0.37 by May 2000. The average level of the spillover index over the previous 12-month period from April 1999 to March 2000 was 0.52, and over the subsequent 12 -month period the volatility spillover index was only 0.36 . As can be seen from Fig. 3, the spillover index then exhibits another upward spike in the aftermath of the September 11th, 2001 terrorist attacks.

As the final illustration, let us focus on the changes in the volatility spillover index around the unprecedented financial market turmoil over the period 2007-2009. In May 2007 , the volatility spillover index reached its maximum value of 0.95 over our complete 84 -year sample period. Then, after having been above 0.70 for more than 2 years, the volatility spillover index suddenly plunged to near-zero levels at the onset of the global financial crisis. The average value of the spillover index was 0.07 over the 12 -month period from September 2007 to August 2008. After Lehman Brothers filed for bankruptcy and the outbreak of the global financial crisis in September 2008, the volatility spillover index surged again and stayed around 0.80 for the ensuing 5 -year period.

To further investigate whether the observed time-variation in volatility spillovers between value and momentum portfolios can be attributed to common economic factors, we next utilize data on economic policy uncertainty, consumer confidence, and stock market liquidity. ${ }^{5}$ Economic policy uncertainty, for instance, has been previously linked to

\footnotetext{
5 The data for the economic policy uncertainty index are obtained from https://www.policyuncertain ty.com/us_monthly.html, the data for U.S. consumer confidence from https://data.oecd.org/leadind/consu mer-confidence-index-cci.htm, and the data for stock market liquidity from https://faculty.chicagobooth.edu/ lubos.pastor/research/liq_data_1962_2018.txt.
} 
momentum returns by $\mathrm{Gu}$ et al. (2018). Table 4 reports the pairwise correlations of VSPC with the economic policy uncertainty index of Baker et al. (2016), the U.S. consumer confidence index, and the aggregate stock market liquidity measure of Pástor and Stambaugh (2003). As can be noted from the table, all three economic factors are strongly correlated with VSPC. Specifically, the correlations in Table 4 suggest that volatility spillovers between value and momentum returns are stronger during periods of high economic policy uncertainty, low consumer confidence, and high stock market liquidity.

Taken as a whole, our results indicate that the intensity of volatility spillovers between value and momentum returns varies considerably over time. We document persistent regimes of low and high volatility spillovers. The time-varying intensity of volatility spillovers is, at least to some extent, linked to economic cycles and common economic factors. Furthermore, we find that the intensity of the volatility spillovers between value and momentum strategies may change substantially in very short periods of time. These sudden upward and downward changes in volatility spillover intensity can be, at least partially, linked to specific economic and geopolitical events and periods of severe financial market turmoil. Overall, these findings are broadly consistent with Diebold and Yilmaz (2009), who document that volatility spillovers between different stock markets are affected by specific economic events and financial crises. ${ }^{6}$

\section{Is there a linkage between volatility spillovers and future returns?}

As the next step of our analysis, we investigate whether there is a linkage between the intensity of volatility spillovers and the returns on value and momentum portfolios. For this purpose, we divide the 1-month-ahead volatility spillover index into the following three spillover regimes ${ }^{7}$ : (1) a low spillover intensity regime wherein the spillover index is below $0.30,(2)$ a medium spillover intensity regime wherein the spillover index takes values between 0.30 and 0.70 , and (3) a high spillover intensity regime where the volatility spillover index exceeds 0.70 . We construct three dummy variables for the three different spillover intensity regimes which take the value of one if the volatility spillover index is in a given regime and zero otherwise. At this point, it is once again important to note that because we operate with a forecast-error variance decomposition using a horizon of 1 month, i.e., $h=1$, we obtain an estimate of the expected volatility spillover intensity over the next month, i.e., at time $t+1$.

We examine the relationship between volatility spillover intensity and returns by successively regressing the returns on the value and momentum portfolios on the three spillover intensity dummy variables:

\footnotetext{
${ }^{6}$ It is worthwhile to note that the volatilities of both value and momentum returns may present a long memory which is typically featuring a slow decay of the autocorrelation functions (see e.g., Qu 2011; Chen et al. 2018). However, in the construction of VSPC, our paper follows Diebold and Yilmaz (2009) and Grobys (2015) by assuming that the higher lag-orders of the employed VAR models ensure that the residual processes of Eq. (2) are stationary white noise processes.

7 We employ the volatility spillover index based on an iteratively updated VAR model with 2 lags and a forecast-error variance decomposition using a horizon of 1 month to classify volatility spillover intensity into different regimes. We do not use the first principal component of volatility spillovers because it is not an ex-ante measure that could be utilized for real-time investment decisions.
} 
Table 5 Value and momentum returns in different volatility spillover regimes

\begin{tabular}{llll}
\hline & \multicolumn{2}{l}{ Volatility spillover intensity } \\
\cline { 2 - 4 } & Low & Medium & High \\
\hline Value returns & $0.35^{* *}$ & $0.46^{* *}$ & $0.59^{* *}$ \\
$t$ stat. & $(2.40)$ & $(2.28)$ & $(2.12)$ \\
Momentum returns & $0.68^{* * *}$ & $0.70^{* * *}$ & 0.24 \\
$t$ stat. & $(3.64)$ & $(2.77)$ & $(0.58)$ \\
\hline
\end{tabular}

The table reports the average monthly returns for the value and momentum factor portfolios in three different volatility spillover intensity regimes. The three different regimes are defined based on the volatility spillover index with lag-order $p=2$ as follows: (1) a low spillover intensity regime if the spillover index is below 0.30 , (2) a medium spillover intensity regime if the spillover index takes values between 0.30 and 0.70 , and (3) a high spillover intensity regime if the volatility spillover index exceeds 0.70 . The sample period is from December 1931 to September 2015. Heteroscedasticity robust $t$-statistics are reported in parentheses

$* * *$, and ** denote statistical significance at the 0.01 , and 0.05 levels, respectively

$$
r_{i, t+1}=\alpha_{1} D_{\text {low }, t}+\alpha_{2} D_{\text {medium }, t}+\alpha_{3} D_{\text {high }, t}+\varepsilon_{i, t}
$$

where $r_{i, t}$ denotes the return on portfolio $i=\{$ value, momentum $\}$ in month $t$, and $D_{l o w, t}$, $D_{\text {medium, },}$, and $D_{h i g h, t}$ are the dummy variables for the alternative volatility spillover intensity regimes defined above.

Table 5 reports the regression results. The estimated coefficients indicate that value returns increase monotonically from the low volatility spillover intensity regime to the high spillover intensity regime. Regardless of the spillover regime, the monthly returns of the value strategy are positive, ranging from 0.35 to $0.59 \%$, and statistically highly significant with the heteroscedasticity robust $t$-statistics being above 2 . The returns on the momentum portfolio, in turn, are substantially higher in the low and medium spillover intensity regimes than in the high spillover intensity regime. In the low and medium spillover intensity regimes, the average monthly return of the momentum strategy is roughly $0.70 \%$, and the high $t$-statistics of the coefficients indicate statistical significance at any level. In contrast, the coefficient estimate for the high volatility spillover intensity dummy is statistically insignificant, indicating that the monthly momentum returns are indistinguishable from zero in high spillover regimes. Finally, it can be noted from Table 5 that the momentum portfolio outperforms relative to the value portfolio in low volatility spillover intensity regimes, while the opposite is true for high spillover intensity regimes. Consistent with the findings of Asness et al. (2013), this inverse relation in portfolio returns across the different spillover intensity regimes implies a negative correlation between value and momentum returns.

\section{A trading strategy based on the volatility spillover index}

Given that the average value returns increase and the average momentum returns decrease with increasing volatility spillover intensity between the two strategies, the expected intensity of volatility spillovers may provide useful information for real-time 


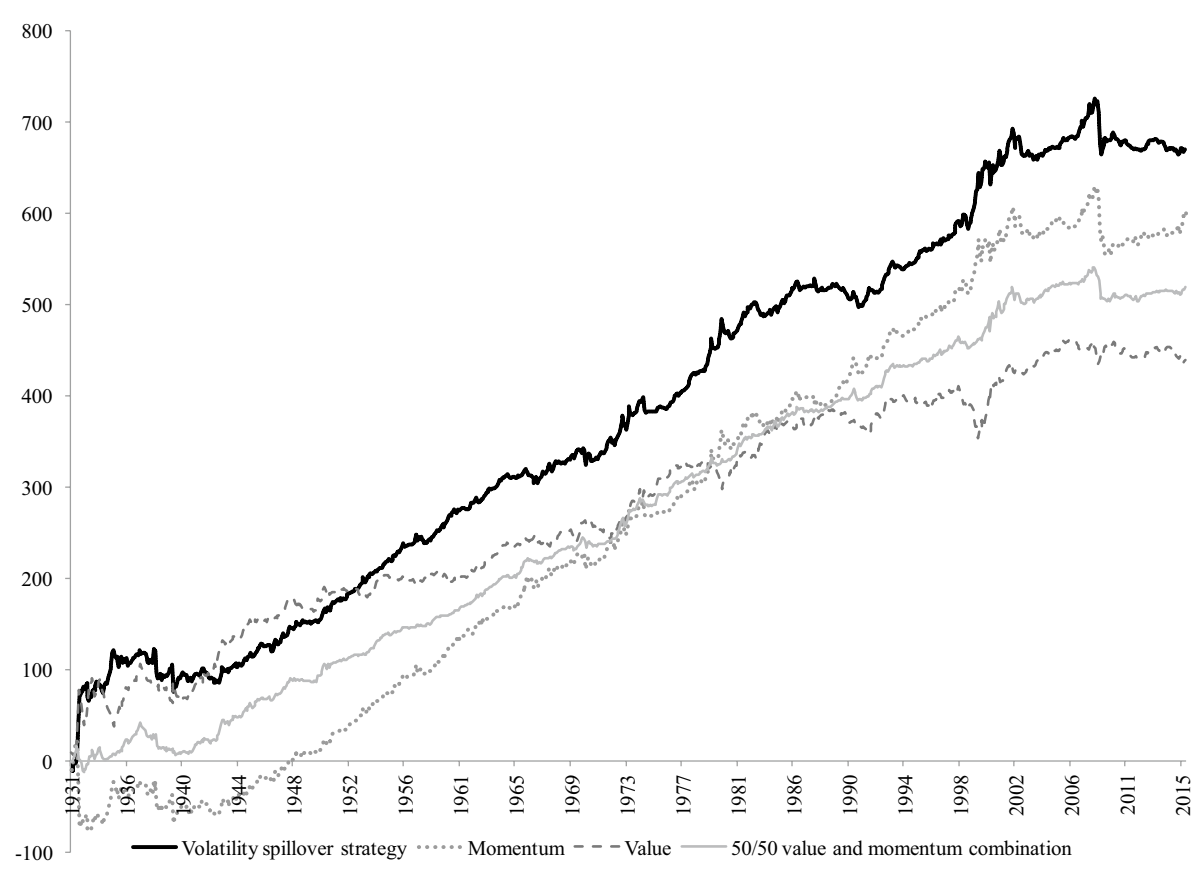

Fig. 4 Cumulative returns. The figure plots the cumulative returns for the following four investment strategies: (1) volatility spillover strategy, (2) zero-cost long-short value portfolio, (3) zero-cost long-short momentum portfolio, and (4) the 50/50 value and momentum combination strategy. The sample period is from December 1931 to September 2015

investment decisions. For instance, it is possible to implement a trading strategy which utilizes the 1-month-ahead forecast of volatility spillovers as a trading signal, and allocates funds into momentum in low volatility spillover intensity regimes and into value in high spillover intensity regimes. We next examine the performance of a trading strategy which uses the volatility spillover index value of 0.70 as a threshold for allocating funds between the value and momentum portfolios so that the strategy is fully invested in momentum when the volatility spillover index is below 0.70 and fully invested in value when the index exceeds 0.70. Over our sample period from December 1931 to September 2015, the proposed trading strategy with the 0.70 spillover index threshold is invested in momentum in 806 months and in value in 199 months. It is again worthwhile to emphasize that the volatility spillover index provides a forecast of spillover intensity in month $t+1$ based on historical data over the previous 60 months, and consequently, this trading strategy is fully implementable.

Figure 4 plots the cumulative returns for the trading strategy based on expected volatility spillovers together with the corresponding returns for the zero-cost long-short value and momentum portfolios and for the 50/50 value and momentum combination strategy of Asness et al. (2013). The figure shows that the volatility spillover strategy has distinctly outperformed the other three strategies over the period the period December 1931 to September 2015. The cumulative return on the volatility spillover strategy over our sample period is roughly $670 \%$, while the corresponding returns on the value and momentum portfolios are about $450 \%$ and $600 \%$, respectively. 
Table 6 Descriptive statistics for monthly returns

\begin{tabular}{lcccc}
\hline & $\begin{array}{l}\text { Volatility spillover } \\
\text { strategy }\end{array}$ & Value portfolio & $\begin{array}{l}\text { Momentum } \\
\text { portfolio }\end{array}$ & $\begin{array}{l}\text { 50/50 value and } \\
\text { momentum combina- } \\
\text { tion }\end{array}$ \\
\hline Mean & 0.67 & 0.44 & 0.6 & 0.52 \\
Median & 0.63 & 0.27 & 0.77 & 0.59 \\
SD & 4.26 & 3.53 & 4.66 & 2.32 \\
Maximum & 35.46 & 35.46 & 18.38 & 13.2 \\
Minimum & -34.58 & -13.28 & -52.35 & -15.34 \\
Skewness & -0.44 & 2.23 & -3.38 & -0.88 \\
Kurtosis & 20.94 & 22.88 & 34.04 & 9.67 \\
Sharpe ratio & 0.16 & 0.12 & 0.13 & 0.22 \\
\hline
\end{tabular}

The table reports descriptive statistics for the monthly returns of the (1) volatility spillover trading strategy, (2) value portfolio, (3) momentum portfolio, and (4) the 50/50 value and momentum combination strategy. The sample period is from December 1931 to September 2015

Table 6 reports the mean monthly returns and other descriptive statistics for the volatility spillover trading strategy, value and momentum portfolios, and the 50/50 value and momentum combination strategy. As can be seen from the table, the mean monthly return of $0.67 \%$ for the proposed volatility spillover trading strategy exceeds the mean monthly returns for the other three portfolios. The Sharpe ratios suggest that the outperformance of the volatility spillover strategy relative to value and momentum strategies is not induced by higher risk.

Nevertheless, Table 6 shows that the Sharpe ratio of the 50/50 value and momentum combination strategy is higher than the Sharpe ratio of the volatility spillover trading strategy. This is not surprising because the strong negative correlation between value and momentum returns documented by Asness et al. (2013) produces a sharp reduction in portfolio variance. On the other hand, the returns for the 50/50 combination strategy, by construction, cannot be as high as or exceed the payoffs of the pure value and momentum portfolios. The proposed trading strategy based on expected volatility spillovers has a very different set-up as the strategy is fully invested in momentum during low and medium volatility spillover intensity months and fully invested in value during high spillover intensity months. As noted above, our strategy allocates funds in the momentum portfolio in 806 out of 1005 months, and we generally capture value payoffs during the adverse months when the momentum strategy generates its lowest (negative) returns. For this reason, the mean monthly return on the volatility spillover trading strategy exceeds the relatively high mean return of the momentum strategy, while the level of portfolio risk must be somewhere between the riskiness of the value and momentum portfolios.

It can be further noted from Table 6 that the return distribution of the volatility spillover trading strategy is much less negatively skewed than momentum returns or the 50/50 combination strategy. This again suggests that the volatility spillover strategy captures relatively higher value payoffs during the adverse months when the momentum strategy generates its most negative returns. Table 6 also shows that the returns of the volatility spillover trading strategy are slightly less leptokurtic than the returns of value and momentum portfolios, albeit the returns of all these three strategies exhibit much higher kurtosis than the 50/50 value and momentum combination strategy. 
Table 7 Fama-French threefactor and five-factor regressions

\begin{tabular}{ll}
\hline $\begin{array}{l}\text { Volatility spillover } \\
\text { strategy }\end{array}$ & $\begin{array}{l}\text { 50/50 value and } \\
\text { momentum combina- } \\
\text { tion }\end{array}$ \\
\hline
\end{tabular}

Panel A: Three-factor regressions, years 1931-2015

$\begin{array}{lll}\text { Intercept } & 0.55^{* * *} & 0.51^{* * * *} \\ & (6.22) & (6.85) \\ M K T & -0.01 & -0.03 \\ & (-0.65) & (-1.53) \\ S M B & 0.05^{*} & 0.06 * * \\ & (1.68) & (2.26) \\ H M L & 0.07 * * & 0.02 \\ & (2.32) & (0.70) \\ R^{2} & 0.01 & 0.20\end{array}$

Panel B: Five-factor regressions, years 1963-2015

$\begin{array}{lll}\text { Intercept } & 0.63^{* * *} & 0.43^{* * *} \\ & (3.59) & (4.86) \\ M K T & -0.10^{*} & -0.06^{* * *} \\ & (-1.84) & (-2.35) \\ S M B & 0.09 & 0.04 \\ & (1.23) & (1.16) \\ H M L & -0.07 & 0.38^{* * *} \\ & (-0.59) & (7.18) \\ R M W & 0.02 & -0.02 \\ & (0.14) & (-0.35) \\ C M A & 0.02 & -0.04 \\ & (0.12) & (-0.58) \\ R^{2} & 0.01 & 0.22\end{array}$

Panel A reports the estimates of the time-series regressions of the monthly returns of the volatility spillover strategy and the 50/50 value and momentum combination strategy on the three Fama and French (1993) risk factors. $M K T, S M B$, and $H M L$ are the standard FamaFrench factors defined as the excess market return, the return difference between small stock and large stock portfolios, and the return difference between high book-to-market stock and low book-to-market stock portfolios, respectively. The sample period in Panel A is from December 1931 to September 2015. Panel B reports the estimates of the time-series regressions of the monthly returns of the volatility spillover strategy and the 50/50 value and momentum combination strategy on the five Fama and French (2015) risk factors. $R M W$ and $M C A$ are defined as the return difference between profitable stock and unprofitable stock portfolios and the return difference between low asset growth stock and high asset growth stock portfolios, respectively. The sample period in Panel B is from July 1963 to September 2015. Heteroscedasticity and autocorrelation robust $t$-statistics are reported in parentheses

$* * *, * *$, and $*$ denote statistical significance at the $0.01,0.05$, and 0.10 levels, respectively 
In order to further investigate the risk properties of the proposed volatility spillover trading strategy, we regress the returns of the volatility spillover strategy and the 50/50 value and momentum combination strategy on the three Fama and French (1993) risk factors:

$$
r_{i, t}=\alpha_{i}+\beta_{i} M K T_{t}+s_{i} S M B_{t}+h_{i} H M L_{t}+\varepsilon_{i, t},
$$

where $r_{i, t}$ denotes the return on strategy $i=\{$ volatility spillover, 50/50 combination $\}$ in month $t$ and $M K T, S M B$, and $H M L$ are the standard Fama-French factors defined as the excess market return, the return difference between small stock and large stock portfolios, and the return difference between high book-to-market stock and low book-to-market stock portfolios, respectively.

The estimates of the time-series regressions of monthly returns on the Fama-French factors are presented in Panel A of Table 7. The estimates show that the returns of the proposed volatility spillover strategy are significantly positively associated with the size and book-to-market factors. Nevertheless, as can be seen from the table, the Fama and French (1993) three factor model leaves large positive intercepts for both the volatility spillover strategy and the 50/50 value and momentum combination strategy. The intercept estimates indicate abnormal returns in excess of 50 basis points per month for both strategies, and the $t$-statistics demonstrate that these abnormal returns are statistically highly significant. Moreover, our estimates suggest that both the volatility spillover strategy and the 50/50 value and momentum combination strategy are slightly exposed to small firms, while the volatility spillover strategy is also exposed to value stocks. Intriguingly, the returns of both strategies are statistically unrelated to excess returns of the market index.

As an additional test, we also utilize the Fama and French (2015) five factor model to assess the performance of the investment strategies by regressing the returns of the volatility spillover strategy and the 50/50 value and momentum combination strategy on the five risk factors:

$$
r_{i, t}=\alpha_{i}+\beta_{i} M K T_{t}+s_{i} S M B_{t}+h_{i} H M L_{t}+r_{i} R M W_{t}+c_{i} C M A_{t}+\varepsilon_{i, t},
$$

where $r_{i, t}$ denotes the return on strategy $i=\{$ volatility spillover, 50/50 combination $\}$ in month $t$, and the two additional risk factors $R M W$ and $C M A$ are defined as the return difference between profitable stock and unprofitable stock portfolios and the return difference between low asset growth stock and high asset growth stock portfolios, respectively. ${ }^{8}$ Panel B of Table 7 presents the estimates of Eq. (11). Overall, the estimates provide further support for the abnormal returns of the volatility spillover strategy. As can be seen from Panel $\mathrm{B}$, the estimated intercepts indicate abnormal returns in excess of 60 basis points per month for the volatility spillover strategy which exceed the abnormal returns of the 50/50 value and momentum combination strategy by about 20 basis points.

Given that the volatility spillover trading strategy captures value payoffs during the months when the momentum strategy generates its lowest returns, and furthermore, the somewhat intriguing pattern of higher-order moments in Table 6, we next investigate whether the strategy's returns are subject to optionality effects and so-called momentum crashes. Following the empirical approach of Daniel and Moskowitz (2016), we estimate the following regression specification separately for the volatility spillover trading strategy, value and momentum portfolios, and the 50/50 value and momentum combination strategy:

\footnotetext{
${ }^{8}$ Due to data availability, the sample period in these additional regressions is from July 1963 to September 2015.
} 
Table 8 Optionality effects

\begin{tabular}{llllll}
\hline Coefficient & Variable & $\begin{array}{l}\text { Volatility } \\
\text { spillover } \\
\text { strategy }\end{array}$ & Value portfolio & Momentum portfolio & $\begin{array}{l}50 / 50 \text { value and } \\
\text { momentum combina- } \\
\text { tion }\end{array}$ \\
\hline$\hat{\alpha}_{0}$ & & $0.74^{* * *}$ & $0.81^{* * *}$ & $0.38^{* * * *}$ & $0.59^{* * *}$ \\
& & $(6.46)$ & $(6.89)$ & $(2.86)$ & $(7.97)$ \\
$\hat{\alpha}_{B}$ & $I_{B-1}$ & -1.24 & 1.24 & $-1.49^{* *}$ & -0.12 \\
$\hat{\beta}_{0}$ & $\tilde{r}_{m, t}^{e}$ & $(-1.06)$ & $(1.55)$ & $(-2.39)$ & $(-0.43)$ \\
& & 0.06 & $0.10^{* *}$ & -0.03 & 0.03 \\
$\hat{\beta}_{B}$ & $I_{B, t-1} \times \tilde{r}_{m, t}^{e}$ & $-0.48^{* * *}$ & $-0.34^{* * *}$ & 0.00 & $(1.01)$ \\
$\hat{\beta}_{B, U}$ & & $(-3.65)$ & $(-2.68)$ & $(0.01)$ & $-0.17^{* *}$ \\
$R^{2}$ & $I_{B, t-1} \times I_{U, t} \times \tilde{r}$ & 0.35 & $-0.68^{* *}$ & $0.56^{* *}$ & $(-2.27)$ \\
\hline & & $(0.73)$ & $(-2.23)$ & $(2.57)$ & -0.06 \\
\hline
\end{tabular}

The table reports the estimates of the time-series regressions given by Eq. (11) for the monthly returns of the (1) volatility spillover trading strategy, (2) value portfolio, (3) momentum portfolio, and (4) the 50/50 value and momentum combination strategy. The sample period is from December 1931 to September 2015. Heteroscedasticity and autocorrelation robust $t$-statistics are reported in parentheses

***, and $* *$ denote statistical significance at the 0.01 , and 0.05 levels, respectively

$$
r_{i, t+1}=\hat{\alpha}_{0}+\hat{\alpha}_{B} \times I_{B-1}+\hat{\beta}_{0} \times \tilde{r}_{m, t}^{e}+\hat{\beta}_{B} \times I_{B, t-1} \times \tilde{r}_{m, t}^{e}+\hat{\beta}_{B, U} \times I_{B, t-1} \times I_{U, t} \times \tilde{r}_{m, t}^{e}+\varepsilon_{i, t}
$$

where $r_{i, t}$ denotes the return on strategy $i=\{$ volatility spillover, value, momentum, 50/50 combination $\}$ in month $t, \hat{\alpha}_{0}$ is the risk-adjusted return of the unconditional model, $\hat{\beta}_{0}$ is the unconditional market sensitivity (i.e., beta coefficient), $\tilde{r}_{m, t}^{e}$ is the excess market return, $I_{B, t-1}$ is an ex ante bear market indicator that equals one if the cumulative market return over the 24 months before month $t$ is negative and zero otherwise, and $I_{U, t}$ is a contemporaneous up-market indicator that equals one if the excess market return in month $t$ is positive and zero otherwise. The parameter of interest in Eq. (12) is $\hat{\beta}_{B, U}$. As noted by Daniel and Moskowitz (2016), a positive and significant $\hat{\beta}_{B, U}$ implies that the examined investment strategy is effectively a short call option on the market during bear markets.

Table 8 reports the estimates of the time-series regressions given by Eq. (12). As can be seen from the table, the parameter estimate for $\hat{\beta}_{B, U}$ is -0.68 for the momentum portfolio and 0.56 for the value portfolio, and both of these estimates are highly significant with heteroscedasticity and autocorrelation robust $t$ statistics of -2.23 and 2.57 , respectively. Thus, consistent with Daniel and Moskowitz (2016), our estimates indicate that the momentum strategy exhibits strong option-like behavior and that the optionality effect is reversed for the value strategy. Turning the focus onto the proposed volatility spillover strategy and the $50 / 50$ value and momentum combination strategy, our regression results demonstrate that neither of these two strategies is subject to option-like behavior and momentum crashes. Most importantly, it can be noted from Table 8 that the estimated $\hat{\beta}_{B, U}$ for the volatility spillover strategy is indistinguishable from zero.

Overall, our results provide considerable evidence that the intensity of volatility spillovers between value and momentum returns can be utilized for implementing a profitable trading strategy. The proposed trading strategy outperforms the value and momentum 
strategies as well as the 50/50 value and momentum combination strategy. The abnormal returns generated by the volatility spillover strategy are in excess of 50 basis points per month relative to the three Fama-French risk factors, and we conclude that the outperformance of the spillover strategy cannot be explained by higher risk.

\section{Conclusions}

In this paper, we take a novel perspective on value and momentum effects by examining volatility spillovers between these two strategies. This analysis is motivated by two streams of literature that focus on value and momentum effects in stock returns and on volatility linkages across and within different segments of financial markets. Given the voluminous body of studies on value and momentum effects and the practical implications of potential volatility spillovers, it is somewhat surprising that volatility interdependencies between value and momentum strategies have been ignored in previous studies. We aim to fill this gap in the literature.

In our empirical analysis, we use data on value and momentum factor portfolios of U.S. stocks over the period December 1926 through September 2015. We estimate monthly realized volatilities for the value and momentum returns, and then employ the volatility spillover index framework proposed by Diebold and Yilmaz (2009) to examine the intensity of volatility spillovers between value and momentum strategies. Our findings demonstrate that the intensity of volatility spillovers between value and momentum portfolios varies considerably over time. Specifically, we document persistent regimes of low as well as high volatility spillovers between value and momentum returns, and our findings also indicate that the intensity of the volatility spillovers may shift substantially in very short periods of time. These sudden changes in spillover intensity can be, at least to some extent, linked to specific economic and geopolitical events and periods of severe financial market turmoil. In the aftermath of major events, the volatilities of value and momentum returns are more likely to be driven by a common uncertainty factor, whereas periods of low volatility spillover intensity tend to coincide with economic recessions.

Furthermore, our empirical findings indicate that the average returns of the value portfolio increase and the average returns of the momentum portfolio decrease with increasing volatility spillover intensity between the two strategies. Given this linkage between volatility spillovers and returns, we propose a simple trading strategy which utilizes the expected intensity of volatility spillovers for allocating funds between value and momentum portfolios. In particular, we use the 1-month-ahead forecast of volatility spillover intensity as a trading signal, and allocate funds into momentum in low volatility spillover intensity regimes and into value in high spillover intensity regimes. The results demonstrate that the proposed trading strategy outperforms and provides considerably higher Sharpe ratios than value and momentum strategies. Perhaps more interestingly, our results indicate that the trading strategy based on expected volatility spillovers generates payoffs that are not subject to option-like behavior and momentum crashes.

Taken as a whole, our paper contributes to the literature by documenting time-varying volatility interdependencies between value and momentum returns. Given the growing literature on momentum crashes and tail risks of investment strategies (see e.g., Bhansali 2008; Daniel and Moskowitz 2016; Xiong et al. 2016; Grobys et al. 2018; Baltas and Scherer 2019), an interesting avenue for future studies would be to examine potential tail risk interdependencies between value and momentum strategies. 
Acknowledgements Open access funding provided by University of Vaasa (UVA). We wish to thank two anonymous referees, Robert Brooks, Denis Davydov, Jared DeLisle, Claudia Zunft, and conference and seminar participants at the 56th Annual Meeting of the Southern Finance Association and the University of Vaasa for helpful comments and suggestions. Part of this paper was written while S. Vähämaa was visiting Florida Atlantic University and the University of Manchester.

Open Access This article is licensed under a Creative Commons Attribution 4.0 International License, which permits use, sharing, adaptation, distribution and reproduction in any medium or format, as long as you give appropriate credit to the original author(s) and the source, provide a link to the Creative Commons licence, and indicate if changes were made. The images or other third party material in this article are included in the article's Creative Commons licence, unless indicated otherwise in a credit line to the material. If material is not included in the article's Creative Commons licence and your intended use is not permitted by statutory regulation or exceeds the permitted use, you will need to obtain permission directly from the copyright holder. To view a copy of this licence, visit http://creativecommons.org/licenses/by/4.0/.

\section{References}

Asness C, Moskowitz T, Pedersen LH (2013) Value and momentum everywhere. J Finance 68:929-985

Baker S, Bloom N, Davis S (2016) Measuring economic policy uncertainty. Q J Econ 131:1593-1636

Baltas N, Scherer B (2019) Tail risk in the cross section of alternative risk premium strategies. J Portf Manag 45:93-104

Barosso P, Santa-Clara P (2015) Momentum has its moments. J Financ Econ 116:111-120

Bartov E, Kim M (2004) Risk, mispricing, and value investing. Rev Quant Finance Acc 23:353-376

Barunik J, Kocenda E, Vacha L (2016) Asymmetric connectedness on the U.S. stock market: bad and good volatility spillovers. J Financ Mark 27:55-78

Bauman WS, Conover CM, Miller RE (2001) The performance of growth stocks and value stocks in the Pacific Basin. Rev Pac Basin Financ Mark Policies 4:95-108

Ben Sita B (2013) Volatility links between US industries. Appl Financ Econ 23:1273-1286

Bhansali V (2008) Tail risk management. J Portf Manag 34:68-75

Bhattacharya D, Li W-H, Sonaer G (2017) Has momentum lost its momentum? Rev Quant Finance Acc 48:191-218

Cakici N, Tang Y, Yan A (2016) Do the size, value, and momentum factors drive stock returns in emerging markets? J Int Money Finance 69:179-204

Campbell Y, Lettau M, Malkiel BG, Xu Y (2001) Have individual stocks become more volatile? An empirical exploration of idiosyncratic risk. J Finance 56:1-43

Capaul C, Rowley I, Sharpe WF (1993) International value and growth stock returns. Financ Anal J 49:27-36

Chen CY, Chiang TC, Härdle WK (2018) Downside risk and stock returns in the G7 countries: an empirical analysis of their long-run and short-run dynamics. J Bank Finance 93:21-32

Chiang TC, Chiang JJ (1996) Dynamic analysis of stock return volatility in an integrated international capital market. Rev Quant Fin Account 6:5-17

Clements AA, Hurn AS, Volkov VV (2015) Volatility transmission in global financial markets. J Empir Finance 32:3-18

Daniel K, Moskowitz T (2016) Momentum crashes. J Finan Econ 122:221-247

Datar V, So RW, Tse Y (2008) Liquidity commonality and spillover in the US and Japanese markets: an intraday analysis using exchange-traded funds. Rev Quant Finance Acc 31:379-393

Diebold FX, Yilmaz K (2009) Measuring financial asset return and volatility spillovers, with application to global equity markets. Econ J 119:158-171

Ewing B (2002) The transmission of shocks among S\&P indexes. Appl Financ Econ 12:285-290

Fama E, French K (1993) Common risk factors in the returns on stocks and bonds. J Financ Econ 33:3-56

Fama E, French K (1998) Value versus growth: the international evidence. J Finance 53:1975-1999

Fama E, French K (2008) Dissecting anomalies. J Finance 63:1653-1678

Fama E, French K (2012) Size, value, and momentum in international stock returns. J Financ Econ 105:457-472

Fama E, French K (2015) A five-factor asset pricing model. J Financ Econ 116:1-22

Galariotis E (2014) Contrarian and momentum trading: a review of the literature. Rev Behav Finance $6: 63-82$ 
Gannon GL (2010) Simultaneous volatility transmission and spillover effects. Rev Pac Basin Financ Mark Policies 13:127-156

Graham B, Dodd D (1934) Security analysis. McGraw-Hill, New York

Greenwood-Nimmo M, Nguyen V, Rafferty B (2016) Risk and return spillovers among the G10 currencies. J Financ Mark 31:43-62

Griffin J (2002) Are the Fama and French factors global or country specific? Rev Financ Stud 15:783-803

Grobys K (2015) Are volatility spillovers between currency and equity market driven by economic states? Evidence from the US economy. Econ Lett 127:72-75

Grobys K, Ruotsalainen J, Aijo J (2018) Risk-managed industry momentum and momentum crashes. Quant Finance 18:1715-1733

Gu M, Sun M, Wu Y, Xu W (2018) Economic policy uncertainty and momentum. In: Proceedings of the 26th annual conference on pacific basin finance, economics, accounting, and management conference (Rutgers University, USA)

Hamao Y, Masulis RW, Ng V (1990) Correlations in price changes and volatility across international stock markets. Rev Financ Stud 3:281-307

Hamilton JD, Lin G (1996) Stock market volatility and the business cycle. J Appl Econom 11:573-593

Harris R, Pisedtasalasai A (2006) Return and volatility spillovers between large and small stocks in the UK. J Bus Finance Account 33:1556-1571

Hur J, Singh V (2016) Reexamining momentum profits: underreaction or overreaction to firm-specific information? Rev Quant Finance Acc 46:261-289

Jegadeesh N, Titman S (1993) Returns to buying winners and selling losers: implications for stock market efficiency. J Finance 48:35-91

Jegadeesh N, Titman S (2001) Profitability of momentum strategies: an evaluation of alternative explanations. J Finance 56:699-720

Jiang G, Li D, Li G (2012) Capital investment and momentum strategies. Rev Quant Finance Acc 39:165-188

Jostova G, Nikolova S, Philipov A, Stahel C (2013) Momentum in corporate bond returns. Rev Financ Stud 26:1649-1693

Moskowitz T, Grinblatt M (1999) Do industries explain momentum? J Finance 54:1249-1290

Pástor L, Stambaugh RF (2003) Liquidity risk and expected stock returns. J Political Econ 111:642-685

Pätäri E, Leivo T (2017) A closer look at value premium: literature review and synthesis. J Econ Surv 31:79-168

Pätäri E, Leivo T, Hulkkonen J, Honkapuro S (2018) Enhancement of value investing strategies based on financial statement variables: the German evidence. Rev Quant Finance Acc 51:813-845

Qu Z (2011) A test against spurious long memory. J Bus Econ Stat 29:423-438

Ribeiro P, Curto J (2017) Volatility spillover effects in interbank money markets. Rev World Econ 153:105-136

Rouwenhorst K (1998) International momentum strategies. J Finance 53:267-284

Sapp T (2011) The 52-week high, momentum, and predicting mutual fund returns. Rev Quant Finance Acc $37: 149-179$

Schwert GW (1989) Why does stock market volatility change over time? J Finance 44:1115-1153

Swinkels L (2004) Momentum investing: a survey. J Asset Manag 5:120-143

Wang Z (2010) Dynamics and causality in industry-specific volatility. J Bank Finance 34:1688-1699

Xiong JX, Idzorek TM, Ibbotson RG (2016) The economic value of forecasting left-tail risk. J Portf Manag 42:114-123

Yu S (2012) New empirical evidence on the investment success of momentum strategies based on relative stock prices. Rev Quant Finance Acc 39:105-121

Publisher's Note Springer Nature remains neutral with regard to jurisdictional claims in published maps and institutional affiliations. 